\title{
Correlations between periodontal indices and osteoporosis
}

\author{
SMARANDA ADELINA PREDA ${ }^{1 *}$, MARIA CRISTINA COMANESCU ${ }^{2}$, DANA MARIA ALBULESCU $^{2 *}$, \\ IONELA TEODORA DASCĂLU ${ }^{3}$, ADRIAN CAMEN $^{4}$, CRISTIAN NIKY CUMPĂTĂ $^{5}$, PAULA PERLEA ${ }^{6}$, \\ NARCIS MIHĂIȚĂ BUGĂLĂ $\breve{7}^{7}$, ELENA LOREDANA STOICA ${ }^{8}$, LELIA MIHAELA GHEORGHIȚA $\breve{1}^{1 *}$, \\ OANA ANDREEA DIACONU ${ }^{1 *}$ and MIHAELA JANA TUCULINA ${ }^{1}$
}

\begin{abstract}
${ }^{1}$ Department of Odontotherapy, Faculty of Dental Medicine, ${ }^{2}$ Department of Anatomy, Faculty of Medicine, Departments of ${ }^{3}$ Orthodontics and ${ }^{4}$ Maxillo-Facial Surgery, Faculty of Dental Medicine, University of Medicine and Pharmacy of Craiova, 200349 Craiova; ${ }^{5}$ Department of Maxillo-Facial Surgery, Faculty of Dental Medicine, 'Titu Maiorescu' University, RO-031593 Bucharest; ${ }^{6}$ Department of Endodontics, Faculty of Dental Medicine,

'Carol Davila' University of Medicine and Pharmacy, 010221 Bucharest; Departments of ${ }^{7}$ Biostatistics and

${ }^{8}$ Dermatology, Faculty of Medicine, University of Medicine and Pharmacy of Craiova, 200349 Craiova, Romania
\end{abstract}

Received August 30, 2021; Accepted September 29, 2021

DOI: $10.3892 / \mathrm{etm} .2022 .11179$

\begin{abstract}
In the pathogenesis of chronic periodontitis, there are general systemic factors which play a major role, such as osteoporosis, with menopause as the most common etiological factor, and other pathological determining conditions for osteoporosis as well (ovary, thyroid and malignant tumors). The aim of the present study was to assess the correlations between periodontal indices and osteoporosis. The study was performed on 35 patients with periodontal disease aged between 45 and 79 years. These patients were divided into two groups: a study group with osteoporosis and periodontal disease $(n=25)$ and a control group with periodontal disease $(n=10)$ only. The periodontal assessment included community periodontal index (CPI), gingival inflammation index (GI), plaque index (PI), body mass index (BMI), bone mineral density (BMD), tooth mobility and tooth loss. Osteoporosis was assessed by dual-energy X-ray absorptiometry. Results were statistically analyzed with Microsoft Excel software and XLSTAT. The results showed that patients in the study group had higher values of periodontal indices, and a highly
\end{abstract}

Correspondence to: Professor Paula Perlea, Department of Endodontics, Faculty of Dental Medicine, 'Carol Davila' University of Medicine and Pharmacy, 17-23 Calea Plevnei, 010221 Bucharest, Romania

E-mail: paula.perlea@gmail.com

Professor Adrian Camen, Department of Maxillo-Facial Surgery, Faculty of Dental Medicine, University of Medicine and Pharmacy of Craiova, 2-4 Petru Rareș Street, 200349 Craiova, Romania

E-mail: adrian.camen@umfcv.ro

${ }^{*}$ Contributed equally

Key words: periodontal indices, osteoporosis, periodontal disease, menopause, statistical analysis significant inverse correlation was observed between the CPI and the tooth loss. Inverse correlations between BMI and tooth mobility, as well as BMI and CPI were determined for the study group. In conclusion, the positive association between BMD and GI shows that the gingival index can be a predictive factor in the occurrence of osteoporosis.

\section{Introduction}

The present study starts from the hypothesis that in the pathogenesis of chronic periodontitis a major role is represented by general systemic factors, such as osteoporosis (OP), with menopause being the most common. Other pathological conditions in young women also constitute determining factors for osteoporosis (ovary, thyroid and malignant tumors) (1-4).

Although the involvement of OP in the alteration of marginal periodontium has not been extensively studied in the literature, some studies have shown that there are clinical and etiopathogenic correlations between OP and periodontal disease (5-7). The most recent classification of periodontal diseases included OP between the systemic disorders which influence the pathogenesis of periodontal disease (8).

As OP is a systemic disease affecting the skeleton, the influence on the upper maxillary and mandible in terms of decreased bone mass and its possible effects on periodontitis progression has been investigated. Both periodontitis and OP are bone resorption diseases and can be seen as a real epidemic condition in the young but also the adult population (5,9-13).

The prevalence of periodontitis has increased, affecting $\sim 80 \%$ of the adult population. Previous findings suggest that OP also affects the upper maxillary and mandible and is a risk factor for periodontal disease and early tooth loss (6).

\section{Patients and methods}

Patients. The cases included in the present study were selected and monitored by an outpatient endocrinology service and a private dental office between March 2016 and December 2019. 
A total of 35 patients, females, aged between 45 and 79 years, were selected from urban and rural areas.

The patients were divided into two groups: a study group with OP and periodontitis comprising 25 patients and a control group without OP and with periodontal disease comprising 10 patients.

Inclusion and exclusion criteria. The inclusion criteria were female subjects, $>45$ years, menopause installed, secondary amenorrhea for at least one year and OP confirmed by dual-energy X-ray absorptiometry (DEXA).

The exclusion criteria included: active cancer, chronic renal failure, hormone replacement therapy for menopause, and confirmed bone disease.

Ethics approval and patient consent. All the patients signed informed consent, containing both the OP treatment and the agreement for inclusion in the study. The present study was designed to include observational and transversal analysis. Each subject had a one-time evaluation. The present study had the agreement of the Ethics Senate and the University of Medicine and Pharmacy of Craiova, Romania, and Scientific Ethics Commission (UMF no. 52/20.04.2018).

Clinical evaluation. Oral cavity examination was performed by a dentist for all the patients included in the present study. The periodontal examination was performed by inspection but also by palpation. The clinical examination revealed the form of the disease by evaluating the clinical attachment level and the inflammatory symptomatology (gingival bleeding on probing). Examination of the swollen marginal periodontium included the assessment of the transformations at the gingival level, including color changes such as the color of the free gum, and of the gum attached. The normal color was pink-coral or pale pink, with various brown tones, depending on the amount of melanin. Color changes included red-burning gum (signifying acute gingival inflammation) and purple-red gum (sign of chronic inflammation).

Changes in the appearance of the gum, which normally has a granite surface, included an orange peel appearance; the glossy, shiny appearance is a landmark of edema. Additionally, the contours, texture and gingival consistency were evaluated.

Clinical attachment level (CAL) values measuring the attachment losses were estimated by probing; this was carried out for each tooth separately, at 6 sites: distal third, middle third, and mesial third of the buccal dental crown surface, as well as mesial third, middle third, and distal third of the oral dental crown surface.

CAL threshold values, used to define a case of periodontitis $>3 \mathrm{~mm}$ on the teeth without gingival recessions, were recorded as established by the 2017 World Workshop on the Classification of Periodontal and Peri-Implant Diseases and Conditions (14) and used to calculate community periodontal index (CPI), which represents the periodontal disease index established by the World Health Organization.

The gingival inflammation index (GI), plaque index (PI), CPI index, dental mobility, and tooth loss were also evaluated.

Periodontal diagnosis. In the periodontal diagnosis, the computation of the GI was performed as described by Löe and Silness (15): 0 indicated normal gums, no inflammation, no discoloration, and no bleeding; 1 indicated mild inflammation, slight change in color and edema, and no bleeding; 2 indicated moderate inflammation, and edema and bleeding; 3 indicated severe inflammation, severe edema, and tendency to spontaneous bleeding.

To estimate the amount of plaque, the Löe and Silness Plaque Index Silness (15) was used: 0, no/plaque; 1, thin plaque layer at the gingival margin only detected by scraping with a probe; 2 , moderate accumulation of plaque within gingival pocket, plaque may be seen with the naked eye; 3 , plaque abundance among the gingival margin and interdental spaces filled with plaque.

The CPI index represents the periodontal disease index, and the evaluation of the periodontal status is made by dividing the teeth on the dental arch into 6 groups called sextants. The coding is set on a scale from 0 to 4 as follows: 0 indicating healthy; 1 indicating bleeding at probing, without periodontal pockets; 2 indicating the presence of supra or sub-gingival calculus, gingival bleeding; 3 indicating the presence of periodontal pockets with a depth of $4-5 \mathrm{~mm}$; 4 indicating the presence of periodontal pockets with a depth $>6 \mathrm{~mm}$.

Dental mobility is an indicator of periodontal status and represents the horizontal or vertical displacement of a tooth beyond its normal physiological boundaries. At periodontal clinical examination, the dental mobility is appreciated by handling of a tooth or with the dental mirror and the following degrees of mobility are noticed: Grade 0 , no apparent mobility; Grade 1, perceptible mobility $<1 \mathrm{~mm}$ buccolingually; Grade 2, mobility between 1 and $2 \mathrm{~mm}$; Grade 3,>2 mm buccolingually.

Bone mineral density (BMD) assessment to establish the diagnosis of osteopenia/osteoporosis was performed using DEXA and the T-score values were evaluated. A GE Lunar Prodigy Advance Bone Densitometer, equipment from GE Healthcare, was used to perform DEXA lumbar measurement. The body mass index (BMI) was computed according to the formula: BMI $\left(\mathrm{kg} / \mathrm{m}^{2}\right)=$ weight $(\mathrm{kg}) /$ height $\left(\mathrm{m}^{2}\right)$. Patients were divided into weight categories as follows: i) underweight: BMI <18.5; ii) normal weight: BMI between 18.5 and 24.9; iii) overweight: BMI between 25 and 29.9; iv) obese: $\mathrm{BMI} \geq 30$.

Statistical analysis. Microsoft Excel software was used for data processing (Microsoft Corp., Redmond), along with the XLSTAT suite for MS Excel (Addinsoft SARL). Secondary data processing included the calculation of fundamental statistical parameters, mean and standard deviation. To perform data normality tests (Shapiro-Wilks and Anderson-Darling) and Student's t-test and ANOVA tests (Bonferroni Correction), module commands XLSTAT were used.

\section{Results}

Patient characteristics. The data relevant to the present study consisted of the age when menopause status was reached, the number of years since menopause was reached, the BMI and BMD. These data are statistically evaluated in Table I.

From the BMI point of view, normal weight subjects in the group with OP and overweight subjects in the control group were observed. BMD showed decreased values in the group with OP $(\mathrm{P}=0.9)$ when compared to the control group 
Table I. Basic characteristics of the study groups.

\begin{tabular}{|c|c|c|c|c|c|c|c|c|c|c|c|c|c|c|c|}
\hline \multirow[b]{2}{*}{ Groups } & \multicolumn{3}{|c|}{$\begin{array}{l}\text { Age at menopause } \\
\text { status }\end{array}$} & \multicolumn{3}{|c|}{$\begin{array}{l}\text { No. of years since the } \\
\text { onset of menopause }\end{array}$} & \multicolumn{3}{|c|}{ BMI $\left(\mathrm{kg} / \mathrm{m}^{2}\right)$} & \multicolumn{3}{|c|}{$\operatorname{BMD}\left(\mathrm{g} / \mathrm{cm}^{2}\right)$} & \multicolumn{3}{|c|}{ T-score } \\
\hline & $\begin{array}{l}\text { Mean } \\
\text { value }\end{array}$ & SD & P-value & $\begin{array}{l}\text { Mean } \\
\text { value }\end{array}$ & SD & P-value & $\begin{array}{l}\text { Mean } \\
\text { value }\end{array}$ & SD & P-value & $\begin{array}{l}\text { Mean } \\
\text { value }\end{array}$ & SD & P-value & $\begin{array}{l}\text { Mean } \\
\text { value }\end{array}$ & SD & P-value \\
\hline $\begin{array}{l}\text { Study } \\
\text { group } \\
(\mathrm{n}=25)\end{array}$ & 45.27 & 3.56 & 0.39 & 21.45 & 9.97 & 0.30 & 23.71 & 5.53 & 0.63 & 0.71 & 0.11 & 0.9 & -2.700 & 0.850 & 0.148 \\
\hline $\begin{array}{l}\text { Control } \\
\text { group } \\
(\mathrm{n}=10)\end{array}$ & 46.5 & 3.24 & 0.32 & 17.85 & 5.06 & 0.48 & 25.04 & 7.19 & 0.52 & 0.75 & 0.12 & 0.87 & 0.540 & 0.310 & 0.014 \\
\hline
\end{tabular}

$\mathrm{SD}$, standard deviation; BMI, body mass index; BMD, bone mineral density.

Table II. Periodontal index values for the study groups.

\begin{tabular}{|c|c|c|c|c|c|c|}
\hline \multirow[b]{2}{*}{ Variables } & \multicolumn{3}{|c|}{ Osteoporosis group $(\mathrm{n}=25)$} & \multicolumn{3}{|c|}{ Control group $(\mathrm{n}=10)$} \\
\hline & Mean value & SD & P-value & Mean value & $\mathrm{SD}$ & P-value \\
\hline GI & 2.83 & 0.51 & 0.91 & 2.4 & 0.48 & 0.83 \\
\hline PI & 2.63 & 0.63 & 0.78 & 2.3 & 0.52 & 0.63 \\
\hline CPI & 2.42 & 0.75 & 0.89 & 1.9 & 0.73 & 0.82 \\
\hline Mobility & 2.1 & 0.61 & 0.68 & 2.33 & 0.73 & 0.74 \\
\hline Tooth loss & 20 & 8.58 & 0.73 & 20.46 & 9.73 & 0.90 \\
\hline
\end{tabular}

GI, gingival index; PI, plaque index; CPI, the periodontal disease index; SD, standard deviation.

$(\mathrm{P}=0.87)$, but the average numerical values showed very small differences.

Periodontal indices. The mean values and standard deviation of the periodontal indices measured are recorded in Table II and the subject groups are stipulated as: the group with OP, and the control group.

Higher values of the periodontal indices were recorded in the OP group (GI, $\mathrm{P}=0.91$; $\mathrm{PI}, \mathrm{P}=0.78$; $\mathrm{CPI}, \mathrm{P}=0.89$; mobility, $\mathrm{P}=0.68$; tooth loss, $\mathrm{P}=0.73$ ) compared to the control group $(\mathrm{GI}$, $\mathrm{P}=0.83$; PI, $\mathrm{P}=0.63$; $\mathrm{CPI}, \mathrm{P}=0.82$ ) except for tooth mobility and loss, which had higher values in the control group (mobility, $\mathrm{P}=0.74$; tooth loss, $\mathrm{P}=0.90$ ).

Correlation between the periodontal indices and the degree of osteoporosis. The correlation between the periodontal indices and the degree of osteoporosis, BMD and BMI in the group with OP and periodontal disease were calculated (Table III). From the analysis, a significant and reasonable correlation between BMD and GI was recorded (0.559), which denotes that BMD represents a predictive factor for the GI score. Correlations between the T-score and GI (0.363), T-score and PI (0.314) and also between GI and PI (0.289) were of small significance.

Inverse correlations. Although the positive correlations were of little relevance, a highly significant inverse correlation between the CPI and tooth loss and also the reasonable inverse correlations between BMI and mobility, and BMI and CPI were evidence that a higher value of BMI is accompanied by a reduction in the degree of mobility and a reduction of the CPI. An inverse but weak correlation, was identified between tooth loss and GI (Table IV).

The analysis of the P-values revealed highly significant statistical correlations for BMI and mobility, BMD and T-score, BMD and GI, CPI and tooth loss and a statistically significant correlation between BMI and CPI (Table IV).

Correlation of $O P$ and periodontal indices. For the control group with periodontal disease the correlation coefficients between the periodontal indices are listed in Table V.

A highly significant correlation was identified between BMD and GI, as for the other parameters there were no meaningful positive correlations, but only a reasonable correlation according with the fast interpretation of the ' $r$ ' Pearson's correlation coefficient: i) $r \in(0 ; 0.2) \rightarrow$ very weak correlation, non-existent; ii) $\mathrm{r} \in(0.2 ; 0.4) \rightarrow$ weak correlation; iii) $\mathrm{r} \in(0.4 ; 0.6) \rightarrow$ reasonable correlation; iv) $\mathrm{r} \in(0.6 ; 0.8) \rightarrow$ high correlation; v) $\mathrm{r} \in(0.8 ; 1) \rightarrow$ very high correlation, i.e., very close relationship between variables or calculation error.

Correlation of degree of mobility and tooth loss. An inverse, highly significant correlation between CPI and tooth loss but 
Table III. Correlation between the periodontal indices and the osteoporosis degree in the group with osteoporosis and periodontal disease.

\begin{tabular}{lcccccccc}
\hline Parameters & Mobility (grade) & BMI $\left(\mathrm{kg} / \mathrm{m}^{2}\right)$ & Tooth loss & CPI & T-score & BMD g/cm ${ }^{2}$ & GI & PI \\
\hline Mobility (grade) & $\mathbf{1}$ & $\mathbf{- 0 . 5 9 1}$ & -0.084 & 0.169 & -0.297 & -0.224 & -0.138 & -0.159 \\
BMI $\left(\mathrm{kg} / \mathrm{m}^{2}\right)$ & $\mathbf{- 0 . 5 9 1}$ & $\mathbf{1}$ & 0.260 & $\mathbf{- 0 . 4 1 7}$ & 0.266 & 0.092 & -0.070 & -0.002 \\
Tooth loss & -0.084 & 0.260 & $\mathbf{1}$ & $\mathbf{- 0 . 7 5 6}$ & -0.217 & 0.072 & -0.323 & -0.022 \\
CPI & 0.169 & $\mathbf{- 0 . 4 1 7}$ & $\mathbf{- 0 . 7 5 6}$ & $\mathbf{1}$ & 0.026 & 0.031 & 0.307 & -0.057 \\
T-score & -0.297 & 0.266 & -0.217 & 0.026 & $\mathbf{1}$ & $\mathbf{0 . 5 1 3}$ & 0.363 & 0.314 \\
BMD g/cm & -0.224 & 0.092 & 0.072 & 0.031 & $\mathbf{0 . 5 1 3}$ & $\mathbf{1}$ & $\mathbf{0 . 5 5 9}$ & 0.149 \\
GI & -0.138 & -0.070 & -0.323 & 0.307 & 0.363 & $\mathbf{0 . 5 5 9}$ & $\mathbf{1}$ & 0.289 \\
PI & -0.159 & -0.002 & -0.022 & -0.057 & 0.314 & 0.149 & 0.289 & $\mathbf{1}$ \\
\hline
\end{tabular}

GI, gingival index; PI, plaque index; CPI, community periodontal index; BMD, bone mineral density; BMI, body mass index. Bold indicates highly significant correlation.

Table IV. P-values for the group with osteoporosis and periodontal disease for correlation coefficients.

\begin{tabular}{lcccccccr}
\hline Parameters & Mobility (grade) & BMI $\left(\mathrm{kg} / \mathrm{m}^{2}\right)$ & Tooth loss & CPI & T-score & BMD g/cm ${ }^{2}$ & \multicolumn{1}{c}{ GI } & PI \\
\hline Mobility (grade) & $<0.001$ & $\mathbf{0 . 0 0 2}$ & 0.689 & 0.418 & 0.149 & 0.281 & 0.511 & 0.447 \\
BMI $\left(\mathrm{kg} / \mathrm{m}^{2}\right)$ & $\mathbf{0 . 0 0 2}$ & $<0.001$ & 0.210 & $\mathbf{0 . 0 3 8}$ & 0.198 & 0.662 & 0.738 & 0.992 \\
Tooth loss & 0.689 & 0.210 & $<0.001$ & $<\mathbf{0 . 0 0 0 1}$ & 0.298 & 0.733 & 0.115 & 0.917 \\
CPI & 0.418 & $\mathbf{0 . 0 3 8}$ & $<\mathbf{0 . 0 0 0 1}$ & $<0.001$ & 0.902 & 0.883 & 0.135 & 0.787 \\
T-score & 0.149 & 0.198 & 0.298 & 0.902 & $<0.001$ & $\mathbf{0 . 0 0 9}$ & 0.075 & 0.126 \\
BMD g/cm & 0.281 & 0.662 & 0.733 & 0.883 & $\mathbf{0 . 0 0 9}$ & $<0.001$ & $\mathbf{0 . 0 0 4}$ & 0.476 \\
GI & 0.511 & 0.738 & 0.115 & 0.135 & 0.075 & $\mathbf{0 . 0 0 4}$ & $<0.001$ & 0.162 \\
PI & 0.447 & 0.992 & 0.917 & 0.787 & 0.126 & 0.476 & 0.162 & $<0.001$ \\
\hline
\end{tabular}

GI, gingival index; PI, plaque index; CPI, community periodontal index; BMD, bone mineral density; BMI, body mass index. Bold indicates highly significant correlation.

also between BMI and the degree of mobility were observed. There was a negative, weak correlation between the degree of mobility and tooth loss and between the T-score and PI (Table VI).

The P-value showed, in the case of the control group, a statistically significant correlation between tooth loss and CPI, and BMD and GI.

\section{Discussion}

Regarding the correlations between BMI and the periodontal parameters in the present study, an inverse correlation between these variables was obtained, indicating that an increase in BMI, and the presence of obesity in women, is accompanied by a low risk of developing periodontal disease.

Positive correlations for both groups were identified only between bone mineral density (BMD) and gingival index (GI). Significant differences were observed for the values of the correlation coefficients, CPI and T-score, between the two groups with much higher value $(r=0.902)$ in the OP group, compared to the control group $(\mathrm{r}=0.214)$. Another observation regarding the correlation between $\mathrm{CPI}$ and $\mathrm{BMI}$ was that for the group with OP the correlation coefficient was positive
(0.038) while for the control group the value was negative $(-0.581)$.

Previous findings have shown this inverse correlation between BMI and periodontal disease (16-18); however, other findings suggest a positive association between obesity and periodontal disease (16-19). The abovementioned studies are limited in the number of subjects studied, thus the conclusions of these studies cannot be extrapolated to the general population. However, the inverse relationship between BMI and periodontitis in both groups in the present study can be emphasized.

The associations between BMD and periodontal indices show in the present study a significant positive correlation between BMD and GI in the two groups studied. For the other periodontal parameters, only the inverse correlations were identified. Previous findings showed an association of BMD and osteoporosis with GI and PI and a weaker correlation between osteoporosis and periodontal probing depth and CAL (20-23).

An inverse correlation between CPI and tooth loss was observed in the two groups, indicating that the CPI with high values is associated with a lower degree of tooth loss. The same finding was observed between CPI and PI in the control 
Table V. Correlations between osteoporosis parameters and periodontal indices in the control group with periodontal disease.

\begin{tabular}{|c|c|c|c|c|c|c|c|c|}
\hline Variables & T-score & Mobility (grade) & $\mathrm{BMI}\left(\mathrm{kg} / \mathrm{m}^{2}\right)$ & CPI & Tooth loss & GI & $\mathrm{BMD} \mathrm{g} / \mathrm{cm}^{2}$ & PI \\
\hline T-score & 1 & -0.457 & 0.253 & 0.214 & -0.142 & 0.028 & 0.014 & -0.238 \\
\hline Mobility (grade) & -0.457 & 1 & -0.616 & 0.429 & -0.333 & -0.117 & -0.189 & -0.094 \\
\hline BMI $\left(\mathrm{kg} / \mathrm{m}^{2}\right)$ & 0.253 & -0.616 & 1 & -0.581 & 0.377 & -0.063 & -0.010 & 0.240 \\
\hline CPI & 0.214 & 0.429 & -0.581 & 1 & -0.684 & 0.117 & 0.051 & -0.218 \\
\hline Tooth loss & -0.142 & -0.333 & 0.377 & -0.684 & 1 & -0.200 & 0.071 & 0.080 \\
\hline GI & 0.028 & -0.117 & -0.063 & 0.117 & -0.200 & 1 & 0.690 & 0.356 \\
\hline $\mathrm{BMD} \mathrm{g} / \mathrm{cm}^{2}$ & 0.014 & -0.189 & -0.010 & 0.051 & 0.071 & 0.690 & 1 & 0.236 \\
\hline PI & -0.238 & -0.094 & 0.240 & -0.218 & 0.080 & 0.356 & 0.236 & 1 \\
\hline
\end{tabular}

GI, gingival index; PI, plaque index; CPI, community periodontal index; BMD, bone mineral density; BMI, body mass index. Bold indicates highly significant correlation.

Table VI. P-value for the control group with osteoporosis and periodontal disease for correlation coefficients.

\begin{tabular}{|c|c|c|c|c|c|c|c|c|}
\hline Parameters & T-score & Mobility (grade) & $\operatorname{BMI}\left(\mathrm{kg} / \mathrm{m}^{2}\right)$ & CPI & Tooth loss & GI & $\mathrm{BMD} \mathrm{g} / \mathrm{cm}^{2}$ & PI \\
\hline T-score & $<0.001$ & 0.184 & 0.481 & 0.553 & 0.696 & 0.939 & 0.970 & 0.509 \\
\hline Mobility (grade) & 0.184 & $<0.001$ & 0.058 & 0.217 & 0.347 & 0.748 & 0.602 & 0.797 \\
\hline BMI $\left(\mathrm{kg} / \mathrm{m}^{2}\right)$ & 0.481 & 0.058 & $<0.001$ & 0.078 & 0.283 & 0.862 & 0.977 & 0.503 \\
\hline CPI & 0.553 & 0.217 & 0.078 & $<0.001$ & 0.029 & 0.748 & 0.889 & 0.545 \\
\hline Tooth loss & 0.696 & 0.347 & 0.283 & 0.029 & $<0.001$ & 0.579 & 0.846 & 0.825 \\
\hline GI & 0.939 & 0.748 & 0.862 & 0.748 & 0.579 & $<0.001$ & 0.027 & 0.312 \\
\hline $\mathrm{BMD} \mathrm{g} / \mathrm{cm}^{2}$ & 0.970 & 0.602 & 0.977 & 0.889 & 0.846 & 0.027 & $<0.001$ & 0.512 \\
\hline PI & 0.509 & 0.797 & 0.503 & 0.545 & 0.825 & 0.312 & 0.512 & $<0.001$ \\
\hline
\end{tabular}

GI, gingival index; PI, plaque index; CPI, community periodontal index; BMD, bone mineral density; BMI, body mass index; Mobility, dental mobility. Bold indicates highly significant correlation.

group, but there was a positive correlation between CPI and $\mathrm{PI}$ in the group with OP, which demonstrates the role of PI in periodontal disease in this group.

In fact, previous findings have shown the positive correlations between the periodontal indices and BMD and other findings showed that there were no significant associations between these variables, i.e., there is no link between osteoporosis and periodontal disease (24-26).

Findings of a histological study suggested that the gingival tissue shows modifications that may be related to inflammation caused by gingivitis or periodontitis on adult subjects: epithelial and underlying connective tissue atrophy, with an increased number of collagen fibers forming thick collagen packs (27).

Although the study of the involvement of OP in the alteration of the periodontium has been little described in the literature, there are studies that support the presence of interdependencies, both clinical and etiopathogenic, among them, the consequences of osteoporosis leading to frequent forms of periodontitis $(28,29)$.

Some authors attempted to demonstrate the connection between the decreased BMD and tooth loss $(30,31)$ and also the deterioration of some periodontal parameters, there are also studies that do not support the presence of this interdependences (32).

The data from the present study on tooth loss on menopausal women are consistent with the results of the observational study conducted by another author (33).

In the present study, the periodontal evaluation was assessed using the CPI index, the gingival index, the PI and tooth mobility, clinical parameters used in other studies such as the one performed by Richa et al (5).

There is a concordance between results of the present study and the results reported by other authors assessing periodontal indices on patients with OP and a control group (29,34-36).

Currently, there is specific treatment for this form of periodontitis associated with OP (37). However, treatment for OP may alter biochemical markers such as osteocalcin (38).

In summary, a positive association between BMD and GI, that is between OP and the GI, shows the GI can be a predictive factor in the occurrence of OP, but it does not demonstrate the correlation between OP and periodontal disease. Severe periodontal attachment loss would likely manifest on postmenopausal women with OP on their lumbar spine. Therefore, it is imperative for dentists to pay attention to the general BMD detected by DEXA for a personalized therapeutic management. 


\section{Acknowledgements}

Not applicable.

\section{Funding}

Not applicable.

\section{Availability of data and materials}

All data generated or analyzed during this study are included in this published article.

\section{Authors' contributions}

All the authors substantially contributed to each of the following aspects of this paper. SAP, ITD, AC, CNC, PP, LMG, OAD and MJT made substantial contributions to the conception and design of the research. SAP, ITD, AC, CNC, LMG, OAD and MJT made substantial contributions to the acquisition, analysis, and interpretation of data for the research. DMA, MCC, PP, NMB and ELS drafted the work, conducted data analysis, and revised it critically for important intellectual content. All authors discussed the results and contributed to the final version of the manuscript. MJT and SAP confirm the authenticity of all the raw data. All authors read and agreed to the published version of the manuscript.

\section{Ethics approval and consent to participate}

The study was conducted according to the guidelines of the Declaration of Helsinki, and approved by the Ethics Committee of the University of Medicine and Pharmacy of Craiova, Romania (approval no. 52/20.04.2018). Written informed consent was obtained from all subjects involved in the present study.

\section{Patient consent for publication}

Not applicable.

\section{Authors' information}

Author SAP is a PhD student at Endodontics, Dental Medicine, University of Medicine and Pharmacy of Craiova, 200349 Craiova, Romania. Author NMB is a PhD student in Biostatistics at Medicine, University of Medicine and Pharmacy of Craiova, 200349 Craiova, Romania.

\section{Competing interests}

The authors declare that they have no competing interests.

\section{References}

1. Preda SA, Nechita F, Comanescu MC, Albulescu DM, Tuculina MJ, Docea AD, Burada E, Vasile RC and Mitroi M: Evaluation of bone turnover and DXA markers in premature ovarian failure. Rev Chim (Bucharest) 70: 2054-2057, 2019.

2. Popescu M, Carsote M, Ghemigian A, Ionovici N, Calborean V, Dinescu VC and Albulescu DM: Calcifediol concentration vs circulating thyrotropin and free thyroxine in human blood of postmenopausal women. Rev Chim 69: 2089-2091, 2018.
3. Albu CV, Pădureanu V, Boldeanu MV, Bumbea AM, Enescu AS, Albulescu DM, Silosi CA and Enescu A: Vascular neurocognitive disorders and the vascular risk factors. J Mind Med Sci 5: 7-15, 2018.

4. Albulescu DM, Ionovici N, Moldovan HR, Demetrian AD, Bala VS, Constantin C, Bumbea AM, Panus C and Albu VC: Muscle metastases from cervical carcinoma-case report. Rom J Morphol Embryol 58: 545-551, 2017.

5. Richa YR, Puranik MP and Shrivastava A: Association between osteoporosis and periodontal disease among postmenopausal Indian women. J Invest Clin Dent 8, 2017.

6. Grocholewicz K and Bohatyrewicz A: Oral health and bone mineral density in postmenopausal women. Arch Oral Biol 57: 245-251, 2012.

7. Phipps KR, Chan BK, Madden TE, Geurs NC, Reddy MS, Lewis CE and Orwoll ES: Longitudinal study of bone density and periodontal disease in men. J Dent Res 86: 1110-1114, 2007.

8. Jepsen S, Caton JG, Albandar JM, Bissada NF, Bouchard P, Cortellini P, Demirel K, de Sanctis M, Ercoli C, Fan J, et al: Periodontal manifestations of systemic diseases and developmental and acquired conditions: Consensus report of workgroup 3 of the 2017 World workshop on the classification of periodontal and peri-implant diseases and conditions. J Periodontol 89 (Suppl 1): S237-S248, 2018

9. Esfahanian V, Shamami MS and Shamami MS: Relationship between osteoporosis and periodontal disease: Review of the literature. J Dent (Tehran) 9: 256-264, 2012.

10. Wang CJ and Mccauley LK: Osteoporosis and periodontitis. Curr Osteoporos Rep 14: 284-291, 2016.

11. Wactawski-Wende J: Periodontal diseases and osteoporosis: Association and mechanisms. Ann Periodontol 6: 197-208, 2001.

12. Guiglia R, Di Fede O, Lo Russo L, Sprini D, Rini GB and Campisi G: Osteoporosis, jawbones and periodontal disease. Med Oral Patol Oral Cir Bucal 18: e93-e99, 2013.

13. Martinez-Maestre MA, Gonzalez-Cejudo C, Machuca G, Torrejon R and Castelo-Branco C: Periodontitis and osteoporosis: A systematic review. Climacteric 13: 523-529, 2010.

14. Tonetti MS, Greenwell H and Kornman KS: Staging and grading of periodontitis: Framework and proposal of a new classification and case definition. J Periodontol 89 (Suppl 1): S159-S172, 2018.

15. Löe H: The gingival index, the plaque index and the retention index systems. J Periodontol 38: (Suppl): S610-S616, 1967.

16. Al Habashneh R, Azar W, Shaweesh A and Khader Y: The relationship between body mass index and periodontitis among postmenopausal women. Obes Res Clin Pract 10: 15-23, 2016.

17. Al-Zahrani MS, Bissada NF and Borawski EA: Obesity and periodontal disease in young, middle-aged, and older adults. J Periodontol 74: 610-615, 2003.

18. Kongstad J, Hvidtfeldt UA, Gronbaek M, Stoltze K and Holmstrup P: The relationship between body mass index and periodontitis in the copenhagen city heart study. J Periodontol 80: 1246-1253, 2009.

19. Khader YS, Bawadi HA, Haroun TF, Alomari M and Tayyem RF: The association between periodontal disease and obesity among adults in Jordan. J Clin Periodontol 36: 18-24, 2009.

20. Ayeda MS, Alsharif AF, Divakar DD, Jhugroo C, Alosaimi B and Mustafa M: Evaluating the possible association between systemic osteoporosis and periodontal disease progression in postmenopausal women. Dis Mon 65: 193-215, 2019.

21. Yoshihara A, Seida Y, Hanada N and Miyazaki H: A longitudinal study of the relationship between periodontal disease and bone mineral density in community-dwelling older adults. J Clin Periodontol 31: 680-684, 2004.

22. Famili P, Cauley J, Suzuki JB and Weyant R: Longitudinal study of periodontal disease and edentulism with rates of bone loss in older women. J Periodontol 76: 11-15, 2005.

23. Pereira FM, Rodrigues VP, de Oliveira AE, Brito LM and Lopes FF: Association between periodontal changes and osteoporosis in postmenopausal women. Climacteric 18: 311-315, 2015.

24. Mashalkar VN, Suragimath G, Zope SA and Varma SA: A cross-sectional study to assess and correlate osteoporosis and periodontitis among postmenopausal women: A dual energy X-ray absorptiometry study. J Midlife Health 9: 2-7, 2018.

25. Suresh S, Kumar TS, Saraswathy PK and Pani Shankar KH: Periodontitis and bone mineral density among pre and post menopausal women: A comparative study. J Indian Soc Periodontol 14: 30-34, 2010.

26. Shum I, Leung PC, Kwok A, Corbet EF, Orwoll ES, Phipps KR and Jin L: Periodontal conditions in elderly men with and without osteoporosis or osteopenia. J Periodontol 81: 1396-1402, 2010. 
27. Andreescu CF, Mihai LL, Răescu M, Tuculina MJ, Cumpata CN and Ghergic DL: Age influence on periodontal tissues: A histological study. Rom J Morphol Embryol 54 (Suppl 3): S811-S815, 2013.

28. Chang WP, Chang WC, Wu MS, Pai JT, Guo YC, Chen KC, Liu ME, Chiu WT and Hung KS: Population-based 5-year follow-up study in Taiwan of osteoporosis and risk of periodontitis. J Periodontol 85: e24-e30, 2014.

29. Juluri R, Prashanth E, Gopalakrishnan D, Kathariya R, Devanoorkar A, Viswanathan V and Romanos GE: Association of postmenopausal osteoporosis and periodontal disease: A double-blind case-control study. J Int Oral Health 7: 119-123, 2015.

30. Renvert S, Berglund J, Persson RE and Persson GR: Osteoporosis and periodontitis in older subjects participating in the Swedish National survey on aging and care (SNAC-Blekinge). Acta Odontol Scand 69: 201-207, 2011.

31. Inagaki K, Kurosu Y, Yoshinari N, Noguchi T, Krall EA and Garcia RI: Efficacy of periodontal disease and tooth loss to screen for low bone mineral density in Japanese women. Calcif Tissue Int 77: 9-14, 2005.

32. Ronderos M, Jacobs DR, Himes JH and Pihlstrom BLJ Associations of periodontal disease with femoral bone mineral density and estrogen replacement therapy: Cross-sectional evaluation of US adults from NHANES III. J Clin Periodontol 27 778-786, 2000
33. Duncea I, Pop D and Georgescu C: Gingival recession in postmenopausal women with and without osteoporosis. Clujul Med 86: 69-73, 2013.

34. Bullon P, Goberna B, Guerrero JM, Segura JJ, Perez-Cano R and Martinez-Sahuquillo A: Serum, saliva, and gingival crevicular fluid osteocalcin: Their relation to periodontal status and bone mineral density in postmenopausal women. J Periodontol 76: 513-519, 2005.

35. Bertulucci Lde A, Pereira FM, de Oliveira AE, Brito LM and Lopes FF: Periodontal disease in women in post-menopause and its relationship with osteoporosis. Rev Bras Ginecol Obstet 34: 563-567, 2012 (In Portuguese).

36. Alves RC, Félix SA, Rodriguez-Archilla A, Oliveira P, Brito J and Dos Santos JM: Relationship between menopause and periodontal disease: A cross-sectional study in a Portuguese population. Int J Clin Exp Med 8: 11412-11419, 2015.

37. Bechir ES, Voinea-Georgescu R, Tuculina MJ, Dascălu IT, Popescu DM, Cojocaru M, Gheorghită LM, Cumpata CN, Raescu M and Gheorghe AC: Clinical-statistical study on the use of a magnesium-terpene-based substance in polymeric trays for periodontal treatment. Revista de Mase Plastice 56: 964-967, 2019.

38. Bechir ES, Tuculina MJ, Carsote M, Bătăiosu M, Raescu M and Cumpata $\mathrm{CN}$ : Clinical data on transitory teriparatide-related hypercalcemia in daily practice treatment for severe menopausal osteoporosis. Rev Chim 70: 3176-3179, 2019. 